\title{
HETEROTOPIA PANCREÁTICA EM VESÍCULA BILIAR: UM RELATO DE CASO
}

\section{HETEROTOPIC PANCREAS IN THE GALLBLADDER: A CASE REPORT}

Clin Biomed Res. 2021;41(4):368-370

1 Universidade de Passo Fundo. Passo Fundo, RS, Brasil.

2 Pontifícia Universidade Católica do Rio Grande do Sul. Porto Alegre, RS, Brasil.

3 Instituto de Patologia de Passo Fundo. Passo Fundo, RS, Brasil.

Autor correspondente: Nathalia Beck Corrêa 175552@upf.br Universidade de Passo Fundo Rua Paissandu, 1932 99010-100, Passo Fundo, RS, Brasil.

\section{Nathalia Beck Corrêa ${ }^{1}$, Rodrigo Alberton da Silva ${ }^{1}$, Julia Belato Teixeira ${ }^{2}$, João Vitor Longo ${ }^{1}$, Alessandra Loureiro Morassutti ${ }^{3}$, Márcio Abreu ${ }^{3}$}

\section{RESUMO}

A heterotopia pancreática é definida como a presença de tecido pancreático em localização topográfica anômala. Essa patologia pode acometer variadas estruturas da cavidade abdominal, mas raramente manifesta-se na vesícula biliar. Até o momento, menos de 40 casos de heterotopia pancreática em vesícula biliar foram relatados na literatura médica. Apresentamos um caso de uma mulher de 25 anos, que realizou uma colecistectomia videolaparoscópica por colelitíase, com exame anatomopatológico que identificou uma heterotopia pancreática. Apesar de rara, a doença deve ser considerada em pacientes com sintomatologia de doenças da via biliar e de doenças pancreáticas e sem diagnóstico após uma investigação de rotina, tendo em vista que o tecido pancreático ectópico está sujeito às mesmas alterações patológicas, manifestações clínicas e complicações encontradas no próprio pâncreas.

Palavras-chave: Pâncreas; Colecistectomia laparoscópica; Vesícula biliar

\section{ABSTRACT}

Heterotopic pancreas is defined as the presence of pancreatic tissue at an anomalous location. This condition may affect multiple structures in the abdominal cavity but rarely appears in the gallbladder. To date, fewer than 40 cases of heterotopic pancreas in the gallbladder have been reported in the medical literature. We present a case of a 25 year-old woman who underwent a laparoscopic cholecystectomy for cholelithiasis, with a pathology test that detected heterotopic pancreas. Despite its rarity, this disease must be considered in cases of corresponding symptoms without a diagnosis after a routine evaluation, considering that ectopic pancreatic tissue is exposed to the same pathological alterations, clinical manifestations, and complications found in the pancreas.

Keywords: Pancreas; Laparoscopic cholecystectomy; Gallbladder

\section{INTRODUÇÃO}

A heterotopia pancreática (HP), pâncreas ectópico ou coristoma pancreático, é definida pela presença de tecido pancreático em localização topográfica atípica, ou seja, sem contiguidade vascular ou mesmo anatômica com o órgão de origem ${ }^{1-3}$. Compreende uma entidade rara, podendo acometer variadas estruturas da cavidade abdominal e, mais infrequentemente, manifestar-se na vesícula biliar ${ }^{2}$. Foram relatados menos de 40 casos de HP na vesícula biliar ${ }^{4,5}$. Apesar de sua origem embrionária, é detectada principalmente na vida adulta. A maioria dos casos são assintomáticos, sendo o exame histopatológico o principal componente diagnóstico ao detectar um achado incidental após explorações cirúrgicas motivadas por outras doenças ${ }^{2,6}$. 


\section{RELATO DE CASO}

Paciente do sexo feminino, 25 anos, buscou atendimento médico apresentando quadro agudo compatível com cólica biliar (dor abdominal intensa, constante e em quadrante superior direito) e associada a náuseas. Ao exame físico, paciente com sobrepeso, sem outras particularidades. Exames laboratoriais sem alterações. Ao exame ultrassonográfico, foi identificado presença de múltiplos cálculos, confirmando quadro de colelitíase. Paciente realizou colecistectomia videolaparoscópica sem intercorrências e recebeu alta hospitalar.

Ao exame anatomopatológico, a peça retirada apresentava dimensões de $6,5 \mathrm{~cm} \times 2,5 \mathrm{~cm}$, fragmentos de cálculos pétreos, mucosa parda e aveludada, com parede medindo $0,3 \mathrm{~cm}$ de espessura, e presença de linfonodo pericístico reacional de $0,5 \mathrm{~cm}$. O exame microscópico identificou colecistite crônica e foco intramural de HP incidental (Figura 1).

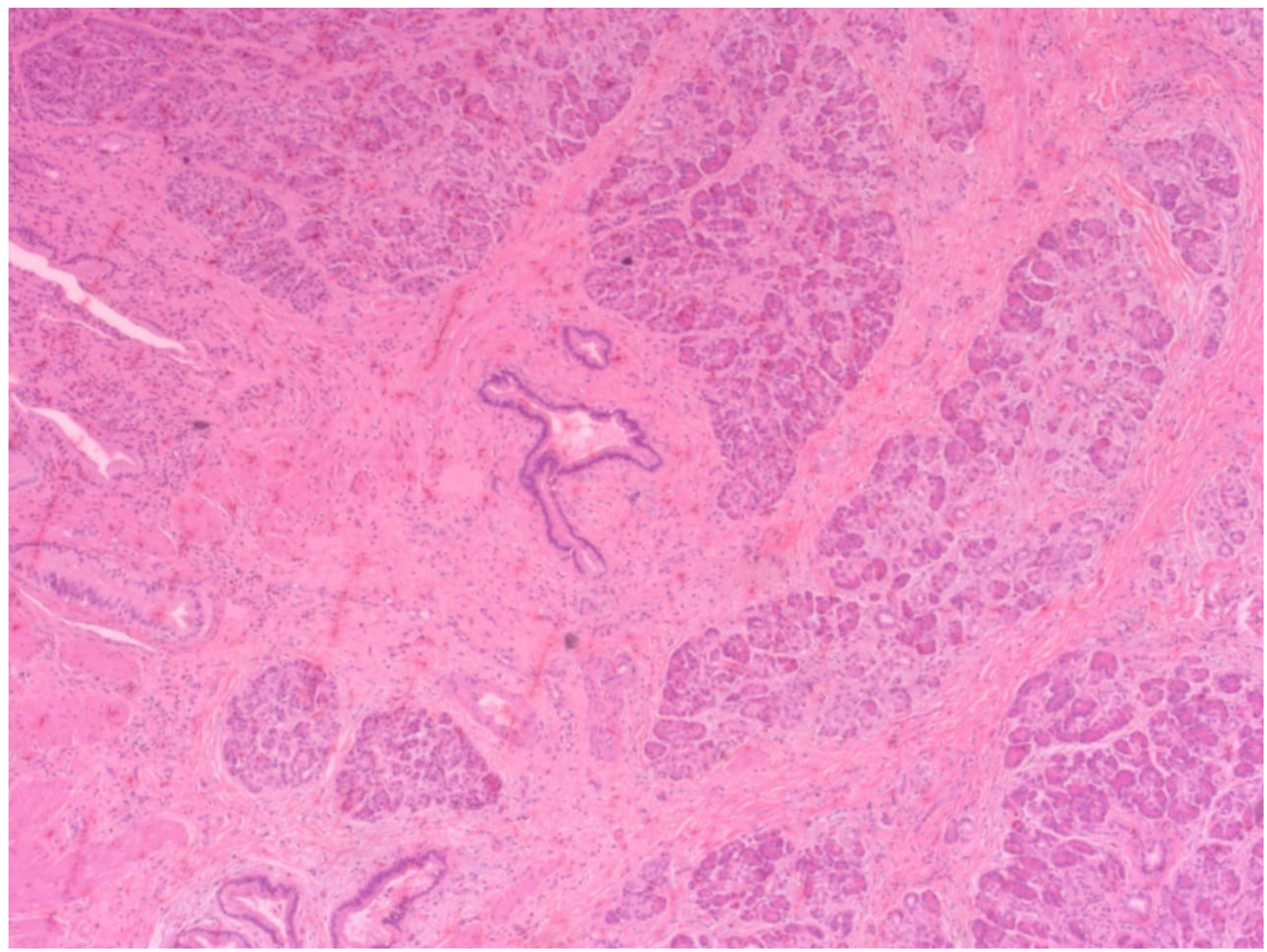

Figura 1: Micrografia óptica em aumento de 25×, coloração de hematoxilina e eosina. Evidencia-se ácinos serosos, ilhotas de Langerhans e ductos intralobulares e interlobulares.

\section{DISCUSSÃO}

A HP em cavidade abdominal ocorre mais frequentemente no estômago, duodeno e jejuno, encontradas em 0,5 a $13,7 \%$ das autópsias do trato gastrointestinal ${ }^{3}$. A localização na vesícula biliar é uma entidade extremamente rara, com poucos casos descritos mundialmente ${ }^{2-4,7,8}$.

Análises de um estudo americano do final do século passado mostraram que de um total de 212 casos de tecido ectópico pancreático em localização abdominal, apenas um desses afetou a vesícula biliar ${ }^{9}$. Mais recentemente, um estudo chinês trouxe o dado de que de 184 casos analisados de HP, apenas $1(0,5 \%)$ estava localizado na vesícula ${ }^{7}$. Nota-se que tanto os dados do século passado quanto os dados atuais evidenciam a raridade do achado.

A fisiopatologia da HP está relacionada ao desenvolvimento embrionário, entretanto o mecanismo específico envolvido na formação da HP ainda não está claro. Uma hipótese é que o tecido pancreático possa migrar para órgãos vizinhos durante a rotação do intestino primitivo, outra hipótese especula que a origem possa estar relacionada às células precursoras multipotentes. 
Microscopicamente, a HP apresenta subtipos (I ao III) conforme a classificação de Von Heinrich. O tipo I ou heterotopia completa, possui todos os componentes celulares do pâncreas (ácinos, ductos e ilhotas de Langerhans); o tipo II, quando estão presentes dois desses componentes celulares; e o tipo III, na presença de um só componente ${ }^{1}$. O tipo histológico do caso abordado compreende ao subtipo I, demonstrando a riqueza microscópica que contempla a histologia pancreática completa (Figura 1). A porção anatômica mais frequentemente acometimetida pela heterotopia pancreática em tecido biliar é o colo da vesícula ${ }^{2,10}$, diferindo do local da paciente neste relato de caso, o fundo.

Mesmo sendo uma entidade de origem congênita, a HP geralmente é descoberta na vida adulta, predominantemente no sexo feminino, entre a quarta e quinta década ${ }^{1,11-13}$. Os casos sintomáticos já relatados descrevem manifestações clínicas sugestivas de litíase, colecistite, obstrução da árvore biliar e perfuração da vesícula ${ }^{2,6}$. Quando sintomática, pode causar um quadro caracterizado por sintomas inespecíficos (dor epigástrica, distensão abdominal, náuseas e vômitos), obstrutivos, hemorrágicos ou pancreáticos e até mesmo achados laboratoriais como aumento da amílase sérica ${ }^{2,10}$.

Por mais que o tecido pancreático encontre-se em localizações distópicas, ele está sujeito às mesmas alterações patológicas, manifestações clínicas e complicações encontradas no próprio pâncreas, como por exemplo, pancreatite, cistos, abscessos e até neoplasia. Já quando presente na vesícula biliar, como no caso aqui relatado, a heterotopia pancreática pode cursar com quadro de colecistite ${ }^{12}$. Cabe ressaltar que a HP é, majoritariamente, um achado incidental que pode coexistir com cálculos biliares e que é diagnosticado por exame anatomopatológico, após cirurgias abdominais por outras patologias, como litíase, processo inflamatório, pólipo ou neoplasia ${ }^{2,6,10,11}$.

Em virtude de seu raro acometimento e poucas referências na literatura, este relato de caso não só enfatiza sua raridade, mas também a necessidade de se relatar mais casos como este. Este relato aponta para a importância de considerar a HP como possível diagnóstico ocasional após procedimentos cirúrgicos e como possível hipótese diagnóstica em pacientes sintomáticos sem diagnóstico após investigação rotineira.

\section{Questões éticas}

Esse trabalho foi aprovado pelo Comitê de Ética da Pontifícia Universidade Católica do Rio Grande do Sul (PUCRS) sob o CAAE 42163320.4.0000.5336 e o parecer número 4.571.386.

\section{REFERÊNCIAS}

1. Bromberg SH, Franco MIF, França LCM, Camilo Neto C. Pancreatic heterotopia in the gall bladder: a case report and literature review. Einstein (Sao Paulo). 2009;7(2 Pt 1):215-8.

2. Elpek GO, Bozova S, Küpesiz GY, Öğüş M. An unusual cause of cholecystitis: heterotopic pancreatic tissue in the gallbladder. World $J$ Gastroenterol. 2007;13(2):313-5.

3. Sanchiz Cárdenas EM, Soler Humanes R, Lavado Fernández Al, Díaz Nieto R, Suárez Muñoz MA. Ectopic pancreas in gallbladder. Clinical significance, diagnostic and therapeutic implications. Rev Esp Enferm Dig. 2015;107(11):701-3.

4. Basrur GB, Utture SK, Deshpande AA. Heterotopic pancreas in the gallbladder. Indian J Surg. 2016;78(5):429-30.

5. Neupert G, Appel P, Braun S, Tonus C. Heterotopic pancreas in the gallbladder. Diagnosis, therapy, and course of a rare developmental anomaly of the pancreas. Chirurg. 2007;78(3):261-4.

6. Bromberg SH, Camilo Neto $\mathrm{C}$, Borges AFA, Franco MIF, França LCM, Yamaguchi N. Pancreatic heterotopias: clinicopathological analysis of 18 patients. Rev Col Bras Cir. 2010;37(6):413-9.

7. Zhang $Y$, Sun X, Gold JS, Sun Q, Lv Y, Li Q, et al. Heterotopic pancreas: a clinicopathological study of 184 cases from a single high-volume medical center in China. Hum Pathol. 2016;55:135-42.

8. Murakami M, Tsutsumi Y. Aberrant pancreatic tissue accompanied by heterotopic gastric mucosa in the gallbladder. Pathol Int. 1999;49(6):580-2.

9. Dolan RV, ReMine WH, Dockerty MB. The fate of heterotopic pancreatic tissue. A study of 212 cases. JAMA Surg. 1974;109(6):762-5.
10. Ferhatoglu MF, Kivilcim T, Kartal A, Filiz Al. A rare pathology mimicking the gallstone: heterotopic pancreas in the gallbladder. Cureus. 2018;10(5):e2659.

11. Klimis T, Roukounakis N, Kafetzis I, Mouziouras V, Karantonis I, Andromanakos N. Heterotopic pancreas of the gallbladder associated with chronic cholecystitis and high levels of amylasuria. JOP. 2011;12(5):458-60.

12. Elhence $\mathrm{P}$, Bansal R, Agrawal N. Heterotopic pancreas in gall bladder associated with chronic cholecystolithiasis. Int J Appl Basic Med Res. 2012;2(2):142-3.

13. Sharma SP, Sohail SK, Makkawi S, Abdalla E. Heterotopic pancreatic tissue in the gallbladder. Saudi Med J. 2018;39(8):834-7. 